\title{
Fluid Minds: Being a Buddhist the Shambhalian Way
}

\author{
AleXAnder McKinley \\ DUKE UNIVERSITY \\ ajm75@duke.edu
}

\begin{abstract}
What are the criteria for counting something as Buddhist? This discipline-defining question has become increasingly perplexing as Buddhism is transmitted across the globe, taking new forms as it adapts to new contexts, especially as non-Buddhists increasingly come to participate in the meditation activities of Buddhist communities in the West. Through an ethnographic analysis of a Shambhala center in the southern United States, this article suggests that the best way to talk about such groups is neither through categorizing membership demographics, nor by ranking the different degrees of Buddhism practiced in Shambhala as more or less authentic, but rather by focusing on how the group ultimately coheres despite inevitable differences in opinion. Thus instead of defining what is 'authentically' Buddhist among Shambhalians, this article tracks the manner in which certain Buddhist forms of signification (especially meditation) are shared regardless of personal religious identities, forging a community through common interest.
\end{abstract}

\section{Keywords}

identity fluidity, Buddhist 'signs', Buddhism in America, Shambhala International

\section{Introduction}

The academic study of Buddhism in North America, begun by Religious Studies scholars in the 1970s, underwent a theoretical evolution in the 2000s that has continued into the 2010s. Until that point, the emerging field relied on accounts that dealt in broad categorizations and sweeping generalizations. The novelty of the subject matter seemed to inspire some scholars to try and explain everything 
at once, trading nuance for exhaustiveness (Gregory 2001, 240). Unfortunately, this approach led to the clumsy categories of 'convert' versus 'ethnic' Buddhist and the proliferation of a number of stereotypes about each that do a disservice to the local particularities of actual practitioners. The present article will align itself with the new theoretical framework presented by scholars such as Jeff Wilson $(2012,18)$ and Thomas Tweed $(2011,20)$ who call for consideration of local and trans-local cultural influences in Buddhist practice, abandoning dichotomous racially-weighted categories that offer little in the way of constructive explanations. The present analysis of one Shambhala center in the southern United States will move beyond static categories by focusing instead on the numerous cultural sources intertwining within daily practice: from Tibetan, to southern United States, to modern pan-United States. culture. The community under study in the present article is one branch of the larger Shambhala International organization, the current instantiation of the late Chögyam Trungpa Rinpoche's Tibetan-lineage Buddhism, which he first brought to the West in the 1960s.

The general term 'Buddhism', though broad, serves a key function in helping scholars of religion sort data, being a filter for the objects and actions that we deem Buddhist by one criterion or another. The criteria of Buddhism, however, can become nebulous in the case of these Shambhalians. Some members of the group do not identify as Buddhist, or even claim to be religious at all. Yet those who come simply to meditate are still welcomed and woven into the fabric of the community. By one criterion or another, they are all Shambhalians. Does this then make them all de facto Buddhists? Studying how the group shares its own criteria for participation provides a way forward with the conventional categories of Religious Studies without becoming overly bounded by them. Whether they selfidentify as Buddhists or not, all Shambhalians ultimately come to participate in certain Buddhist forms of life common in the United States. Such things include most prominently the practice of meditation, but may also extend to vegetarian diets or a belief in merit-making and rebirth, to name just a few. These processes of signification may be coded in either secular or Buddhist terms in the mind of any one member of the Shambhala center, yet such signs are still comprehended by the group as a whole. Thus we might say that Shambhalians who claim they are not Buddhist are certainly correct, but they are also not un-Buddhist.

This brings us to the title of the present article, which is in homage to anthropologist E. Valentine Daniel's first book. It is useful in this case to consider Daniel's understanding of the fluidity of culture and interpersonal exchange:

\footnotetext{
Man himself is a sign ... not a closed, completed entity. He is ready to connect with, to enter into dialogical relationships with other selves and other signs; when he does so connect, he significantly reconstitutes himself. The same is true of culture - as a web of signification it is one with the process of signification itself. Thus, culture is ultimately an open-ended process ... a trafficking in thoughts, a trafficking in signs. (Daniel 1984, 41-42)
}

This conception of culture as a morphing amalgamation of shared signification within a particular group helps describe the Shambhalian way of being. The goal of this article is to show what sort of signs (Buddhist or otherwise) make a person a Shambhalian, how these people and signs arrive and are assimilated, and how signs are passed along to others. Not every member need traffic in every sign, nor 
reconstitute themselves in exactly the same way upon reading the signs of others, for we all have our personal idioms of interpretation, yet the general trend shows Buddhist elements expressed and received by members via linguistic and material media, allowing the collective to cultivate a common Shambhalian outlook. Deeming such signs Buddhist is simply a reflection of the way that the community is physically, materially, and philosophically presented as such. Those on the outer edges of the Shambhala center may attend less frequently, be less fluent in the Tibetan terminology, or interpret their own practice as non-religious, but by continuing to participate, they inevitably traffic in the Buddhist market of signification prominently at play in Shambhala. This may be a productive way to think of the terms Buddhist and Buddhism outside of a conception of religion tied to a consciously internalized individual state, bound to parameters of one identity at the expense of all others. It is a way of defining religious groups in terms of a set of central concepts and signs to which members relate themselves in various degrees of peripheral adherence, rather than conceiving of religious identity as an all or nothing affair (Cho and Squier 2013, Saler 1993). There are indeed many identities at work in the Shambhala center. As this article will stress below through the language of intersecting cultural flows, no Shambhalian participates exclusively in Buddhist forms of life. Rather, all are embedded in a web of local and trans-local cultural networks, from the mountains of Tibet to the foothills of Appalachia, and it is within these networks that their Buddhism is lived. ${ }^{1}$

Considering the above theoretical focus on how communities cohere through signification, it seems an appropriate point to delve into an account of this Shambhala center in one of its regular group settings. Much of this ethnography was conducted around a somewhat amorphous subgroup of the larger Shambhala community - attendees at the Sunday morning meditation sessions. There was a group of regulars who attended almost every week, with other members participating irregularly, some at least once a month, others with longer periods of absence. I chose the Sunday meditation group to study in particular because of this organic ebb and flow to its membership. There is little pressure to socialize and the event is free and open to the public, so it always attracts a contingent of non-members. At least, they are not members in any formal sense, but many ultimately become part of the group one way or another (e.g., by volunteering for door sentry duty during meditation sessions, making it a point to attend the monthly post-meditation tea and discussion, or even simply joining the email listserv). Whether or not they ever choose to enroll in classes and become de juro members, by continually participating in the Sunday group they increasingly traffic in Buddhist forms of signification. In this way, the Sunday Shambhalian subgroup best exemplifies the central problematic discussed above, showing that the criteria from which we construct religious groups must also accommodate those who identify as non-religious. Being a Buddhist the Shambhalian way does not always mean being a Buddhist, if one takes this latter sort of being as equivalent with self-applied labels used to express identity to others. Being a Buddhist in the sense of this article's title is instead a description of a certain form of sociality. It is to be Buddhist not necessarily in name, but in signs.

1. While this article focuses on lived Buddhism in the United States and the scholarship surrounding it, the theory presented here of understanding Buddhist affiliation via the concept of shared signs transmitted through cultural networks could be applicable in any context. 
The following scene will present some of the recurring characters in the present ethnography, along with their motivations for participating in Shambhala. This scene is something of a composite. Much of the dialogue below was spoken on my second visit to the center, but a few explanations of why some of the regulars had been drawn to meditation practice at the center were delivered to me during later conversations. In other words, not all the Shambhalians offered this much information about themselves all at once in the larger group setting described below, but certain stories came out gradually as we would go out to lunch together in smaller groups and I asked questions about their lives. For the purposes of rhetorical ease, I have integrated some of these narratives into the single account below so that each person is properly introduced at the start. That said, the most dramatic introduction in the following vignette did happen that day, an important point that will be discussed more below. This scene is the only composite in the article. The other vignettes are reported exactly as I remembered them immediately after meeting with the group. I took shorthand notes during conversation, and after we all went our separate ways I would race to my desk to reconstruct the entire encounters. In this way, the scenes below might be considered polished field notes. Of course, not every moment of our discussions revolved around topics pertinent to this article. Where conversation has been omitted, I have used the conventional typographical break of three asterisks. As I was not using a tape recorder, the fickle nature of memory (and handwriting without looking) is always a worthy caveat, but I have hoped to temper the weaknesses of my own mind by collaborating with the Shambhalians themselves, who read my reconstructions and provided feedback and amendments where necessary. In the interest of anonymity, all names have been changed and the geographic location has been generalized. Not identifying the specific locale under study was the compromise I struck with the leadership of the center, who were concerned that an article on the Sunday meditation sub-group alone would not adequately represent the diverse range of programming offered by the center - from discussion groups, to yoga, to workshops on cultivating mindfulness in everyday life.

These aforementioned activities form part of the wide span of services contained within the Shambhala International organization, which includes over two hundred centers scattered across Europe and North and South America. Originally named Vajradhatu by Chögyam Trungpa, Shambhala International (which coined its current moniker in 2000) includes a number of 'Dharmadhatu' centers, established to instruct and guide people on the 'Vajradhatu' path of Tibetan Buddhist teachings. Included alongside these religious aspects, Shambhala International also offers a secular approach to meditation known as Shambhala Training, very popular at the center studied here, involving the practical cultivation and application of calm and compassion, exemplified by course titles such as 'Meditation in Everyday Life', 'Contentment in Everyday Life', 'Joy in Everyday Life', etc. Additionally, Shamabhala International offers a wide range of meditative artistic activities, known as the Nalanda Path, including dance, archery, photography, and tea ceremonies, all drawn from a diversity of Buddhist cultural backgrounds (e.g., Indian, Tibetan, Japanese, etc.). While the demographics of this article might have looked very different had I chosen to study these services of Shambhala International as a whole, the identity dynamics of this particular Sunday medi-

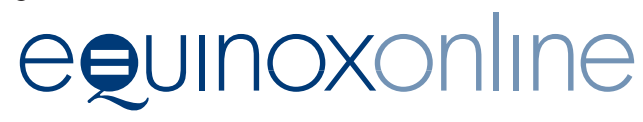


tation subgroup are reflective of the center's ability to assimilate new members and build a community of diverse beliefs bonded through shared Buddhist signs, presenting a microcosm of Shambhala International's larger agglutinative nature.

\section{A Shambhalian meditation and discussion group}

On the third Sunday in September 2012, I visited the Shambhala center for only the second time. I was curious about a discussion event scheduled to occur following two hours of morning group meditation. I arrived just as meditation was set to begin, somewhat disheveled due to riding my scooter there in the rain. Upon arriving, still wiping raindrops from my glasses, I was greeted by Walt, ${ }^{2}$ a man in his 50s who was later described by one Shambhalian as the 'mayor' of the center. He fulfilled the role of umdze that day by leading us in meditation.

'Welcome back. You're just in time for the chanting, since I know you enjoyed it so much last time', he said with a smile.

'Oh, I wouldn't miss it', I responded, and Walt laughed his usual gregarious high-pitched laughter, which he is quick to award to almost any utterance that slightly resembles a joke. I had come to the meditation session the week before and, being the only person to arrive so early, had sat in a slightly awkward silence while Walt did all the vocal work of the opening chants, following along with the text and enjoying the way the slight twang in his accent negotiated the Tibetan vocabulary and lineage names.

This Sunday we also began with brief introductory chants and then spent the next two hours in silent śamatha meditation, alternating between sitting and walking - a transition marked by Walt ringing a sonorous bowl-shaped bell positioned next to his cushion at the front of the room. The rest of us sat facing Walt and the main shrine, above which hangs an image of the Buddha, flanked by pictures of Chögyam Trungpa and his son Sakyong Mipham. The group was small, occupying about eight of the twelve cushions laid out in the meditation room.

After the two hours, we were encouraged to move to an adjacent room to take tea and then return and sit in a circle for a short reading from a book by Pema Chödrön, a nun housed in Shambhala's Gampo Abbey in Nova Scotia and a favorite author among many Shambhalians of this center and elsewhere (Eldershaw 2007). Dorothy was handling the reading today, a soft-spoken, late middle-aged woman with long graying hair and spectacles.

'Well, I was planning to read a selection from Comfortable With Uncertainty, but I can't seem to find my copy. I guess that's a lesson in uncertainty.' We all laugh. 'Instead I will read from When Things Fall Apart.' More laughter. 'Also by Pema Chödrön.' Dorothy read several paragraphs and then we all sat and pondered it for a few moments. I got the impression that she had prepared some comments for the lost reading and was unsure of what sort of exegesis to offer on this particular excerpt. Walt suggested that we instead go around the circle and offer our names and what drew us to the center. He began:

I came into the center in 1993. I've always felt some sort of connection with a religious path. I was searching. I was raised a fundamentalist Christian. A Seventh Day Adventist. And then in college I thought, this isn't any fun. You couldn't dance

2. All personal names of participants at the Sunday morning group have been changed. 
between Friday night and Saturday night. You couldn't go out to eat. You couldn't really do anything except read the Bible. But when I got to college all I wanted to do was party. It was more fun. But then after college ... I graduated in 1982 by the way ... after college I got tired with the party scene, so I was searching for something more, going to different groups. These gurus would come dressed in white and everything, but I never felt any connection to them. I also tried a Course in Miracles. ${ }^{3}$ And that was ok. They did a little meditation with that, but it was just a little bit, like 5 minutes. Well in 1993, Pema Chödrön came here [he said in a voice that relayed a certain amount of disbelief that such an event even happened]. I went to her talk and what she was saying sounded a lot like A Course in Miracles. She talked about learning to accept bad things and learning to let good things go, too. The overall message was be nice to everyone. Pema Chödrön was just so open-hearted. You could see her vulnerability ... and also her willingness to just stay with that. And I thought, 'Hey, maybe this is something.' I really connected to her. Now I've worked up to meditating for three hours a day.

Dorothy, also a veteran member of the center, smiled and nodded at Walt and explained her own motivations:

I started coming to the center in 1994, at the urging of Walt. I was going through some difficulties at the time. My 16-year-old daughter fell in with a bad crowd. I used to call them 'redneck dopers.' [Dorothy used air quotes.] I was looking for meaning and answers. I stumbled across Pema Chödrön's book When Things Fall Apart and it really inspired me. Then I came to the center and started meditating. Meditation helped me to connect with my suffering. Meditation increased my sense of empathy. It helped me understand that all human beings are just looking for happiness in their lives. I was even able to better understand the people that my daughter was hanging out with. They were no longer the enemy because I understood that they were just trying to find happiness, too. We are all just trying to find happiness and meditation helps me realize where it lies.

Robert, who appeared to be in his early 30s, offered his story next, considerably shorter than Walt or Dorothy's had been. Overall, Robert was one of the more reserved members of the Shambhala center:

I've been coming to the center for the past two years. I also sometimes go to the Zen center nearby. I would say my practice is very self-centered right now. I'm really worried about fixing myself at the moment, and so I'm not very focused on cultivating non-attachment right now and I don't really concentrate on being compassionate toward others. I'm trying to get myself right first. You know, understand myself as a person and where I fit into the world.

Jennifer, another younger member in her late twenties, spoke next:

I've been coming to the center for the last three years. I had gone to an Episcopalian church as a kid, which I enjoyed, but once I moved to Catholic school in $4^{\text {th }}$ grade, I became somewhat disillusioned with strictly defined religious identities. The nuns were harsh disciplinarians and confession sessions seemed to me to miss the point of actually working to change a person's behavior. In my early twenties

3. Based on the 1975 book of the same name by Helen Schucman. 
I was feeling kind of depressed and spent a lot of my time drinking and smoking in the evening. I had tried other meditation programs in the past, but they would never stick. It was only once my mom and I went to the Shambhala retreat center in Vermont that I was like, 'holy shit'. I think what was missing before was a sense of compassion for myself and learning how to treat yourself with gentleness. That really helped me because before I would do a practice for a while and then start dwelling on past mistakes and go back to drinking and smoking fairly quickly. But treating yourself with gentleness and also being part of a community where people meditate as a group helps you to stick with it.

The next person in the circle was Milton, who could not have been older than his mid-30s, yet spoke in resigned weighty tones, eyes downcast, explaining how his life was filled with trouble:

This is my first time at the Shambhala center or doing anything similar. I've never meditated before, but I felt like I needed to try something. I am undergoing a midlife crisis of my own making. I've pretty much wrecked my marriage through selfishness. I have a two year old daughter and my wife is two months pregnant, and I feel like I need to fix things before it's too late.

Milton's comments changed the tone of the group sharing and Walt asked him to say more. What drew him to Shambhala in particular?

Well, I was living a really frantic life and it was hurting my family. I saw the error of my ways after reading A New Earth by Eckhart Tolle [a recent Oprah's Book Club selection] and I realized I needed to change myself. Of course, by that point my wife had already asked me to move out, so I have to show her I'm serious about changing. I knew I needed to do something. I found Shambhala on the internet and I came today to help myself improve the way I treat others and to try and escape a frantic mindset. I'm just not sure how I can forgive myself.

He spoke these last words staring at the hardwood floor and shaking his head. Walt and the others nodded along and empathized. Walt: 'Well it takes time, you know. After nineteen years only now am I starting to become comfortable with unpleasant feelings. Or not comfortable with them, but at least able to be present to them through meditation. I found meditating was impossible without the forgiveness aspect.' 'Yeah, I'm just not sure how I can forgive myself', Milton repeated with a sigh, sounding broken. 'Well you know getting down on yourself, thinking "I fucked up", that whole trip is bullshit', Walt offered. Milton nodded. 'I came today because I do want to find reconciliation and I think I'm also seeking some sense of community to help.' 'Good. I think you need to be here. It will get better.'

Everyone thanked Milton profusely for sharing his story and encouraged him to keep practicing meditation. The next person to introduce himself seemed to tailor his own stories to what Milton had just shared. George appeared to be in his 60s and spoke about meditation helping him through a dark time in his life:

I first stumbled across an open Shambhala meeting nineteen years ago as a recovering addict. I had wrecked my life too and I felt like I was at rock bottom, so I definitely know where you're coming from. [He gestured toward Milton]. All I can say is 'hang in there'. Keep sitting; keep practicing. Meditation helps to unravel 
your negative thoughts and trust me that you can learn to forgive yourself. You just have to take it one day at a time.

When the group broke up shortly thereafter, Walt, Robert, and George immediately went over to Milton. They asked him to join them for lunch and George even made sure that Milton had a place to stay, saying he remembered the days when he had to spend nights in his car. I left the center struck by what I had just witnessed, something I had certainly not expected when the discussion began with a reading from Pema Chödrön. What I thought might develop into a discussion about Buddhist teachings ended up being a session of empathetic group support for a lost soul and a new meditation convert. For these Shambhalians, it seemed that meditation was, among other things, a healing technique and that the center could sometimes (though of course not always) resemble a self-help network.

The six people described above are obviously not the only clientele of the center, or even of the Sunday meditation crowd, but some are regular members of the center and overall the scene indicates a selection of the sort of people attracted to the center. Many Shambhalians - like Walt and Jennifer - have had previous experience in some sort of Christian tradition, leaving that religion either because they never considered themselves particularly attached to it, or because they found it too limiting for one reason or another. Additionally, some Shambhalians - like Dorothy, Robert, George, and Milton - were initially drawn to the center because they were experiencing some sort of trauma or crisis in their lives and were looking for a technique to calm their minds, increase their compassion for others, or simply seek general quiescence. Overall, membership at the center is quite fluid. People come and go, perhaps staying away for months at a time and then coming back weekly for the next several months. Some are dedicated attendees of the weekly group meditation sessions, while others prefer the conversation circles or yoga sessions that occur during the weekdays. Some, like Walt, have taken all the courses of the official Shambhala International meditation curriculum. ${ }^{4}$ Others, like Jennifer, have only completed the first few levels of courses. And still others have been attendees of the meditation sessions at the center without ever taking a Shambhala course or donating monetarily. No matter their level of experience or involvement, the center is always prepared to receive them.

\section{Reflections on the visit}

In this way, the Shambhala center provides a space for different degrees of Buddhism - an umbrella that shelters a spectrum of enthusiasms for Buddhist practices, from those who are interested in meditation purely as a self-help technique, to those who self-identify as Buddhist and subscribe fully to a cosmology of karma, rebirth, and guardian deities. Additionally, as was mentioned above, another function of the center is to provide support for those undergoing trials and tribulations. The Shambhala center can be a support group as much as

4. These include courses in the 'Shambhala Training' path mentioned above, as follows. I. The Heart of Warriorship: Level I: The Art of Being Human, Meditation in Everyday Life; Level II: Birth of the Warrior, Contentment in Everyday Life; Level III: Warrior in the World, Joy in Everyday Life; Level IV: Awakened Heart, Fearlessness in Everyday Life; Level V: Open Sky, Wisdom in Everyday Life. II. The Sacred Path: Great Eastern Sun, Windhorse, Drala, Meek, Perky, Outrageous and Inscrutable, Golden Key; Warrior Assembly. This is all a residential program slightly less than two weeks in duration. See: <http://www.shambhala.org/shambhala-training.php>

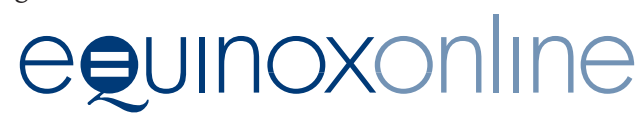


it is a space for religious practice. Milton's immediate absorption into the group was a fascinating event to witness so early in my fieldwork. It happened before I had even introduced myself and explained my reason for being there, so neither the confession nor the group's reaction could have been put on simply for the presence of an official observer. It was fortuitous to witness, for such dramatic confessions do not happen often at the Shambhala center, but the key point to consider is that the group is equipped to handle the more raw manifestations of others' suffering when they do occur. The empathetic response of the group to a stranger's plight was immediate. The fact that members approached him afterward and took him out to lunch shows how adept the group is at integrating a new face into the fold.

This absorptive tendency of the Shambhala center is what facilitates the multiplicity of different Buddhist identities at work in the group. Milton, for example, formally became a Shambhalian when he enrolled in the first level of meditation training soon after becoming affiliated with the center. Yet based on conversations with him, I do not believe he was ever moved to mark his religious identity as Buddhist, but more likely understood himself as appropriating a technique of Buddhist meditation to provide mental healing. After reading a draft of this article, he emphasized to me that he indeed had improved greatly after that first day, and that the Shambhala teaching of self-forgiveness 'was my entrance to inner peace'. In the margins next to the final paragraph in the above vignette, Milton wrote 'Enlightened Society' - which is the end goal of Shambhala Buddhism more broadly - along with his interpretation of this first empathetic response by the members of the center to his plight as he understood it about a half-year afterward:

I would go so far as to say how it was an unexpected yet exact application of the kindness and gentleness practice [taught in Shambhala]. That underscores how the teachings guide people to respond in the moment. Suppose Dorothy brought her book and went with her prepared statement ...

Milton highlights the luck of my witnessing the event in the first place. If Dorothy had not been forced to adapt to the uncertainty of her missing book by exchanging her prepared comments for group introductions, then Milton may have never shared his problems in the communal setting. But when he did, surely creating a moment of social uncertainty for himself and others present, Shambhalians again adapted with aplomb, immediately conveying support and understanding, folding Milton into the support of the group. In part then, being a Shambhalian means cultivating a type of sociality where one is able to respond in the moment with equanimity and compassion.

It is also key that this response was not overbearing, nor at all contingent upon Milton committing to some internal religious transformation or formally identifying himself as a Shambhalian to others. This certainly seemed to appeal to Milton, whose concluding comments on a draft of this article explain:

One big reason Milton kept coming back was because there was no emphasis on the categorization or individual interest level in the lineage. It was all a-la-carte. Choose what you want to take on and if you don't aspire to attain another level, that's just as ok, very non-judgmental. 
This Shambhalian fluidity is the reason we cannot draw the borders around our conception of Buddhism too heavily. That misstep leads to further problems, for an exclusive rather than inclusive definition of Buddhism puts participants like Milton in an ambiguous non-category. When the criteria for deeming whether or not someone or something is 'Buddhist' become vague in this way, it often leads to nebulous discussions of authenticity. This article asserts that questioning the authenticity of a Buddhist group is not an especially productive line of argumentation, and that the problem of locating an authentic Buddhism can be diffused in the first place if one understands the minimal criteria for group participation to involve a relative fluency in Buddhist signs rather than an interiorizing of Buddhist precepts and an exterior trumpeting of Buddhist identity.

Just as Daniel noted that 'man himself is a sign', continually reconstituting himself as he enters into dialogical relationships and receives the signs of others, so Shambhalians develop an affinity for meditation (thus trafficking in the Buddhist sign most essential for the cohesion of this particular group) and come to reconstitute themselves as ambassadors for meditation, wishing to share this practice with others. Yet the group still allows for a wide range of interpretations and opinions about what this meditative sign means personally to the practitioner, granting the Shambhala center an especially effective assimilative power in an age of individualistic authenticity (Taylor 2007, 475). The Shambhalian goal of bringing about an enlightened society does not therefore involve active proselytizing as such, but more of a casual 'this worked for me, and so might work for you' pitch toward curious newcomers. This inclusive method allows a diversity of identities - Buddhist and non-Buddhist, religious and atheist - to exist together as a single group of practitioners, sharing in a form of Buddhist signification that can be assimilated into a variety of personal interpretive idioms.

Thus the goal is not to pass judgments about who counts as Buddhist and who does not, but rather to discover precisely how Buddhism works for its American adherents. This can be done by determining which practices are most popular, the cultural channels through which they arrive, and what sort of functions they can perform in daily lives, regardless of whether practitioners self-identify as Buddhists. The case of the Sunday discussion circle above points to several such cultural channels, whether they involve the draw of charismatic figures like Pema Chödrön, the results of an internet search, or the inspiration of an Oprah's Book Club selection. ${ }^{5}$ These are some of the avenues through which new members are not only drawn to Shambhala initially, but also through which they remain engaged with Buddhist thought, integrating it into their everyday lives. Such an approach in favor of lived experience provides a check against defining Buddhist categories too normatively. The concept of 'Buddhist ethics', for example, cannot be viewed in the Shambhalian context only through the lens of precepts regarding conduct as they might appear in a standard Pāli or Tibetan canonical text. ${ }^{6}$ In other words, the abstraction of a textbook Buddhism is not what is at stake here (Fronsdal 2002). Rather, focusing

5. Lest one presume that the link between Eckhart Tolle and Buddhist thought is purely a product of Western imagination, it should be noted that his self-help books for achieving mental quiescence have been recommended to me by certain Sri Lankan Buddhists as well. The effect of an 'Oprahdorsement' is global.

6. Though even in these texts, reflecting natural ambiguities of the lived contexts in which they were composed, ethics are more complex than only formal precepts. 
on the rough ground of lived Buddhism is meant to show how people negotiate their desires to act well toward themselves and others within a world containing countless other demands that might interrupt these ethical goals. The question at hand is one of proper balance between self and world. To this end, the following section will explore how Buddhist teachings are paradoxically not only assimilated through the channels of consumerist individualism, but also serve to temper some of the negative side-effects of our fast-paced and individualistic age - namely, by easing mental anxiety, cultivating universal ethical outlooks, and tempering capitalist drives toward materialism for certain members of this center.

\section{Vignettes showing cross-cultural flows and ethical living}

A group of us stood outside the center after Sunday meditation deliberating on where to go to lunch. Milton was describing the difficulties he had in meditation that morning. I had noticed him leave about halfway through. Instead of going home, however, he sat on the porch outside the center and waited for the rest of us to finish.

'I couldn't control my thoughts', Milton said when Walt asked why he had left early. 'They were all so negative and filled with guilt. I couldn't settle my head down.'

'Well, you're not actually supposed to try and control your thoughts', Walt said. 'You can just kinda let them come and go.' 'And you're not supposed to leave either', Robert added.

'What do you mean?' asked Walt.

'I mean, if your mind is going everywhere you're just supposed to sit and stay with it. Not just leave.'

Walt nodded. 'Trust me, Milton. It will get better, you just have to keep coming back and practicing.' Robert nodded along to this advice.

\section{soge}

Robert drove Walt and me to lunch.

'I hope none of you are vegans', he said as we opened the doors to his new car. Walt and I said we were not. 'Because my seats are made out of dead animals.'

I laughed at his leather joke.

'But really I do feel guilty about that sometimes.'

As we began to drive away from the center I asked Robert what he does when he's not meditating.

'Feel guilty about driving around with dead animal seats', he joked.

'He does!' piped in Walt from the backseat.

'No actually I'm a slave.'

'A slave?' I asked surprised.

'A slave to the banking system.'

Walt from the backseat: 'What? You're a slave?' 
'I'm a slave to my bank and in order to earn money to be able to keep my house and my car, I have to constantly be working.'

'Well, that's not how I feel about my bank at all', Walt said with a certain sense of wonder. 'Not at all.'

and

Walt, Robert, and I sat down to lunch with George, Milton, and Jennifer. I noticed Walt's lime green t-shirt. Its humor seemed somewhat Buddhist:

When life gives you lemons,

KEEP THEM

Because, hey, free lemons.

We ate outside at a table in the sun. The conversation shifted between our respective distastes for politics, what football games we were planning to watch that afternoon, questions about my own work with Sri Lankan Buddhism, and new apps on iPhones (everyone had their own out on the table and I suddenly felt a bit like a Luddite). Walt read aloud a text message from another Shambhala member: 'Hey Walt, sorry I couldn't sit with you this morning. I decided to go to yoga instead.'

Talk of phones spurred Robert to tell us about a new app he downloaded called Equanimity. It keeps track of his meditation with a timer and calculates weekly sitting time totals. He showed Walt the app and Walt looked it up in the app store:

'It costs $\$ 5$ !? You must be rich', he joked.

Milton started to talk about the new iOS 6 - an operating system for smart phones.

He said he was dying to upgrade his phone.

'Even after sitting in meditation last week?' Walt asked with a laugh.

'Well I still want it; now I'm just less anxious about it.' All laugh. 'But look. Look how long it takes the photo app on my phone to load.' Milton taps it with his finger and counts off ' $1-1,000,2-1,000,3-1,000$. Look at that; a full three seconds.'

'That is long', George acknowledges.

'So the first tangible benefit of starting meditation is feeling less anxious about waiting three seconds for your phone to load?' I asked, getting a laugh. 'Hey, in this day and age, that's important; three seconds matter', I added.

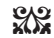

I tried to steer the conversation toward lived ethics, asking these Shambhalians how their understanding of Buddhism or insights from meditation became incorporated into their daily lives, whether through treating others with more compassion, or being less attached to the materialism of consumer America.

Milton was not sure whether meditation had helped him with his problems yet.

'Well, I remember the first day you came you seemed really scattered. Has that gotten any better?' I asked.

'Uh ... I'm not sure. It's probably helped a little bit. Those were really some incredibly shitty weeks in my life. Some of the worst days of my life.'

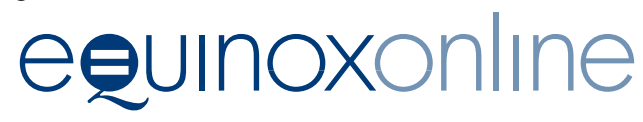


'It was brave of you to go and sit with your thoughts', Jennifer added and all nodded in assent.

Walt said he's proud of Milton. 'You look a lot better. Really. You look much more relaxed. And his karma is turning around for the better, too', Walt added earnestly, turning toward me. 'You know his brother's place recently flooded, but the new meditation cushion he bought from the Samadhi store wasn't touched by the water.'

I asked Walt about how Buddhism helps him in his relationships with others.

'Do you know what a bodhisattva vow is?' Walt asked.

'I know what a bodhisattva is ...'

'Yeah ... Steely Dan', George joked. Laughter.

'Well I know a little bit more than that', I leaned forward to defend myself, but then thought better and sat back to play dumb. 'But what's the vow you're talking about?'

'Well, you know how we believe that we are reborn over and over and have many lifetimes?' Walt asked in his characteristic drawl. I nodded, pondering his use of the inclusive pronoun 'we', thinking how fully he had come to identify himself with Buddhism. 'Well, the bodhisattva takes a vow that he will not be free of that rebirth until all beings are enlightened and are also free. I take this vow every morning now to remind me to act with compassion. It's like a practice to recite the vow. The idea is that by saying it over and over somehow it sinks in ... But it's hard ... hard to know the most skillful thing to do in a situation. So I make mistakes. You know, it's not just about putting others first. It's also about not condemning yourself.'

'So can you think of any anecdotes - '

'What's an anecdote?'

'Uh ... like a short story ... can you think of any examples from your day-to-day life of how your meditation practice has changed the way you react to things? Like you think to yourself, 'I would have gotten upset over this before, but now I accept it."

'Oh my god, yeah. That happens constantly. All the time. I do something wrong, or my workers will make a mistake ... if I get upset, it's a sign something's awry.' Walt paused to think about this some more. 'It's like skillful means, you know? What's most helpful in the situation, whether to a job relationship, or to completing an individual task. Getting angry is not the best choice. It's also about learning to forgive yourself.'

The self-forgiveness aspect resonated with Jennifer, who added her own take on the benefits of practicing Shambhala Buddhism:

It's just like there's less guilt, less dwelling on bad things from the past. Now I find myself living more in the moment. Just living in the now and taking each experience as it comes. I don't have to worry so much about my past or my future or even be bothered by consumerism and the rushed nature of society. I can use the tools I gained from mindfulness practice to deal with things as they come and handle situations from moment to moment.

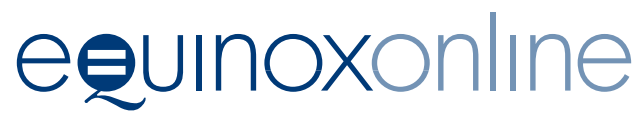


Robert, on the other hand, hesitated to say his practice was making him more compassionate. He still saw his main goal as working through personal issues for himself:

Yeah, so even though I'm very self-centered with my practice now, I can still see it begin to bloom from there and affect other areas of my life. My interest in meditation sort of grew out of a lot of therapy for depression and anxiety and a whole bunch of other stuff. Before I started meditating I noticed that I would buy a lot of stuff to cope. Like really expensive music equipment, for example. I'd get that dopamine rush from buying something new and then a few weeks later it would just be gathering dust and I'd be focused on that next fix of buying something else. Even though I haven't been consciously trying to do this, I've found that my meditation practice has helped me buy less stuff and has also encouraged me to start getting rid of some of the stuff I acquired, just getting it out of my place and reducing the clutter of things in my life.

The conversation moved to tonglen, a popular form of meditation at the Shambhala center that involves concentration on suffering and negativity during the in-breath, and healing and forgiveness on the out-breath (Varela and Depraz 2003, 220-225). Tonglen can be directed toward the general suffering of the world, or the particular problems of an individual.

'I was doing tonglen for my aunt who has cancer and she's getting better! The doctors said she was going to pass away, but she's improving', Jennifer explained.

'Well, she's definitely going to pass away', Walt interjected.

'Really?' Jennifer seemed confused.

'Yeah, she'll pass away, and you'll pass away, and I'll pass away, and even this guy here will die', he said, wagging his thumb in my direction.

'Oh, well, yeah, but I mean that she's not going to die within the next few months.'

'Yeah, I know what you mean. I was practicing tonglen at work the other day. I was working on this guy's pool and his wife had a stroke and had to go to the hospital. Lost movement on one whole side of her body.'

'This happened while you were there?' I asked Walt in surprise.

'Yeah, it was kind of a crazy situation. So I went back to finish working on the pool and while I was working I was doing tonglen for this woman, trying to help her.'

\section{跑象}

Robert gave me and Walt a ride back to the center. Knowing Walt listens to a Pema Chödrön CD everyday in his pickup truck, Robert turned to me and said: 'Watch this, it will blow Walt's mind.' He then remotely activated his iPhone by voice to play a lecture by Pema Chödrön on the teachings of Śāntideva through the stereo system in his car. Walt was indeed thoroughly impressed.

Many of my conversations with these Shambhalians unfolded like the above accounts. Granted, there was likely more direct discussion of Buddhist teachings because I was asking questions along those lines, but I also silently listened to conversations at the center and found Buddhism permeating many interactions, emerging through technology, humor, storytelling, or explanations of events -

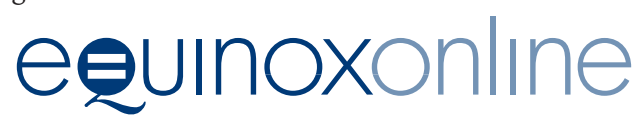


like when Walt proposed that Milton's new meditation cushion was spared from a flooded apartment due to an increase in positive karma, or when Jennifer suggested that tonglen may have helped alleviate her aunt's cancer, with Walt agreeing but reminding her of the impermanence of all our lives. These are some of the Buddhist signs that the whole group can share in conversation and practice, even if not all subscribe personally to a Buddhist cosmology. Buddhism comes via new media to these practitioners (Meditation - there's an app for that!), but it is also based on centuries-old traditions, such as tonglen practice or the ethical writings of Śāntideva (even if the latter comes via a Pema Chödrön lecture). At the same time that Buddhism is delivered by modern consumer channels, it also helps to temper addictions to consumerism, giving practitioners like Robert, who expressed anxiety over his indebtedness to banks, meditative rather than material pathways to happiness. Being a Buddhist the Shambhalian way is ultimately about learning to live peacefully within the pushes and pulls of the modern world. A confluence of different cultural streams and intellectual discourses, from the temples of Tibet to the couches of psychoanalysts, comprise the Shambhala lineage that has become so central to the lives of these Buddhists. If the path of a modern bodhisattva is (as Chögyam Trungpa believed) to help bring about an enlightened society by understanding how the mind works, then the lived Buddhism of these Shambhalians represents the treading of a few first steps in that direction. Likewise, if the path of a scholar studying lived religion is to understand how Buddhist thought works on the minds of its practitioners, then detailed analyses of the ways shared practices and symbols facilitate group cohesion and individual edification seem to be the best way forward.

\section{Conclusions}

Part of the reason I decided to undertake this ethnographic study was out of dissatisfaction with approaches taken by the scholarly community to the study of Buddhism in the United States (Layman 1976, Prebish 1979, 1999, Tweed 2002, Nattier 1997, Cheah 2011, Skriletz 2012, Baumann 2002, Numrich 1996). While many of these scholars used ethnography as a methodology, their published works focused mainly on classification and categorization rather than descriptions of lives. The articles and books present the many different typologies of Buddhists and what makes them different rather than accounts of how Americans actually go about being Buddhist in the first place. Although the beginnings of any new subfield initially entail broad descriptions and generalized categories so as to indicate directions for more specified research, the study of Buddhism in the United States was overdue for theoretical advancement. The shift toward using anthropology to provide in-depth analyses of lived Buddhism within single communities is already underway (Storhoff and Whalen-Bridge 2010, Wilson 2012, Hori 2010). Ideally, this study of some southern United States Shambhalians represents another piece in this new mosaic of specificity. At the very least, this project spares us from any new categories and has hopefully shown the limitations of generalized classifications when it comes to capturing the nuance of lived religiosity and community building.

The above ethnographic evidence upsets abstracted categories by showing a wide range of engagements with Buddhism under one roof, thus trading the awkwardness of imposed classifications for an analytical framework that seeks 
the intersection of different cultural influences - old and new, West and East, Buddhist and otherwise. It is the combination of these various influences that creates a collective like Shambhala Buddhism, and studying these cultural strands in tandem reveals how being a Shambhalian means living Buddhism in a particular way - with gentle compassion for self and others, cognizance of a Tibetan lineage, and a general fluidity that helps practitioners peacefully navigate modern exigencies. ${ }^{7}$ Buddhism is practiced at different speeds beneath the roof of the center, but whether they self-identify as Buddhist or not, all adherents share forms of signification that bind them as a community, and all seem to share a common understanding of the most important Shambhalian sign - the practice of meditation. It would be helpful for scholars to take cues from this sort of practical mindset and refuse to end their inquiries with conclusions about Buddhist typologies. Instead, typology should be no more than a starting point from which one can move forward to discern more critical questions of how and why Americans go about being Buddhists upon or beyond the cushion.

It may be helpful to end with one final ethnographic vignette that captures some of the recurring themes in this article, that is, how the disagreements and differences of opinion that inevitably arise in casual discussions of Buddhism are ultimately diffused and subsumed by shared material and meditative forms of signification. The following conversation occurred after another Sunday discussion session, though this one was very different from the one that opens this article. This time, a person of high rank in the Shambhala International organization visited the center. As one member put it, if Walt was considered the mayor of the center, then she would be the regional governor. She delivered a talk on Buddhism using a number of military metaphors. Based on the questions people posed, it was clear that not everyone at the center understood why she thought this was a good analogy until it became clear that she was talking about a literal spiritual military the dorje kasung, another aspect of Shambhala International that Chögyam Trungpa instituted after being inspired while observing military drills in Scotland. It is a uniformed group of Shambhalians whose retreats include military-style camping and sessions of marching meditation. The casual discussions that sprung up after the talk showed that not everyone understood the appeal of the dorje kasung practice. Particularly skeptical were those who only came for the meditation practice and were not interested in assigning themselves a religious identity.

After the talk broke for tea, I approached Bill to ask why he came to Shambhala last month after sitting at the nearby Zen center for so long. He explained that the Zen center was more 'traditional' and that they had more ritual elements to their practice, which did not interest him much.

'I'm more interested in the pure practice of meditation without all the extra stuff added on. Then again, that talk we heard today shows that Shambhala has its own stuff going on. It's basically like a new religion.'

7. Although ethnicity and socio-economic statuses have not been the focus of this article, it should be noted that the demands of the modern world dealt with at the Shambhala center discussed in this article are those experienced by a predominately (though not exclusively) white middle-class population. Although there is a range within this class at the center from blue collar workers to college professors - a comparative study with another, more diverse Shambhala center may provide further insight into modern problems Buddhist practice helps navigate, beyond those of this relatively privileged subculture. 
'What?! What do you mean a new religion?' Two others converged on our conversation. One was Jeffrey, a long-time attendee of the center with a non-religious interest in meditation. The other was Mary, a full-fledged Shambhalian Buddhist. The air became thick with tension. I nonchalantly bobbed my tea bag up and down and tried to let this play out.

'I mean it has all these additions to it on top of the basic meditation practice', Bill explained.

Mary countered. 'But I wouldn't say it's a new religion. It has ... I mean ... it's basically Buddhism.'

'Well it's a form of Buddhism', Bill clarified

'But it's not a new religion. It's basically Tibetan. Just Tibetan Buddhism.'

Bill politely acquiesced to this and Mary walked away still shaking her head somewhat. Jeffrey took over the questioning, though from a slightly different angle. Now it was a discussion between two meditators who did not identify as Buddhist: "What makes you say that this is a religion? Meditation is a practice. When I think of religion, I usually think of belief.'

I wanted to interject with all of the various beliefs associated with Buddhism - Walt's belief in rebirth, for example - but I held my tongue, thinking it wiser to see how these two resolved their conversation.

Bill: 'Yes, it's true that Buddhism at its core is not about belief; it's a practice. But there is all this stuff that gets added. It doesn't really bother me, otherwise I'd be off sitting by myself, but I just ignore all the extras and focus on the practice. Really I totally agree with your point. I think we approach meditation in a very similar way.'

Jeffrey: 'Right. If you don't like it you can just take your cushion and leave. Like me, for example, I've been coming here now for, oh, about 8 or 10 years. I've never taken any of the training levels or classes or anything. I just come for meditation.'

The two then redirected their conversation to the different types of meditation cushions and why Bill brings his own (because it has ergonomic memory foam). They left for the other room so that Jeffrey could try it out for himself.

Sipping tea, I stood and thought about the fascinating fact that two people took issue with Bill's offhanded characterization of Shambhala as a new religion for wholly different reasons. Mary because he said new religion, and Jeffrey because he said religion. It was quickly becoming clear that there is no one way to be a Shambhalian, nor a consensus about what Buddhism entails, what kind of Buddhism the Shambhala lineage represents, or which of its beliefs and practices are the most important, save perhaps everyone's agreement on the importance of meditation - the sign that binds.

I wandered back over to Mary, who is in charge of childhood education programs at the center. She gave me her email in case I wanted to ask questions. 'I have like five email addresses, but this is my Buddhist email.' Once I clarified that I was doing a project on the center, she made sure to remind me: 'Well don't say that this is a new religion. That's just nonsense', and left shaking her head once again.

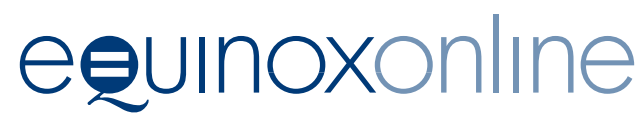




\section{Acknowledgements}

Many thanks to professors Leela Prasad and David Need, as well as the anonymous readers of Buddhist Studies Review, who offered invaluable feedback on drafts of this article.

\section{Bibliography}

Baumann, M. 2002. 'Protective Amulets and Awareness Techniques, or How to Make Sense of Buddhism in the West.' In Westward Dharma: Buddhism Beyond Asia, edited by C. S. Prebish and Martin Baumann, 51-65. Berkeley: University of California Press.

Cheah, J. 2011. Race and Religion in American Buddhism: White Supremacy and Immigrant Adaptation, AAR academy series. New York: Oxford University Press.

Cho, F., and R. K. Squier. 2013. 'Religion as a Complex and Dynamic System.' Journal of the American Academy of Religion 81(2): 357-398. http://dx.doi.org/10.1093/jaarel/ lft016

Daniel, E. V.1984. Fluid Signs: Being a Person the Tamil Way. Berkeley: University of California Press.

Eldershaw, L. P. 2007. 'Collective Identity and the Postcharismatic Fate of Shambhala International.' Nova Religio: The Journal of Alternative and Emergent Religions 10(4): 72-102. http://dx.doi.org/10.1525/nr.2007.10.4.72

Fronsdal, G. 2002. 'Virtues without Rules: Ethics in the Insight Meditation Movement.' In,Westward Dharma: Buddhism Beyond Asia, edited by. C. S. Prebish and Martin Baumann, 285-306. Berkeley: University of California Press.

Gregory, P. N. 2001. 'Describing the Elephant: Buddhism in America.' Religion and American Culture: A Journal of Interpretation 11(2): 233-263. http://dx.doi.org/10.1525/ rac.2001.11.2.233

Hori, V. S. 2010. 'How Do We Study Buddhism in Canada?' In, Wild Geese: Buddhism in Canada, edited by J. S. Harding, V. S. Hori and A. Soucy, 12-38. Montreal \& Kingston: McGillQueens University Press.

Layman, E. M. 1976. Buddhism in America. Chicago, IL: Nelson-Hall Publishers.

Nattier, J. 1997. 'Buddhism Comes to Main Street.' The Wilson Quarterly (1976-) 21(2): 72-80.

Numrich, P. D. 1996. Old Wisdom in the New World: Americanization in Two Immigrant Theravada Buddhist Temples. 1st ed. Knoxville: University of Tennessee Press.

Prebish, C. S. 1979. American Buddhism. North Scituate, MA: Duxbury Press. . 1999. Luminous Passage: The Practice and Study of Buddhism in America. Berkeley: University of California Press.

Saler, B. 1993. Conceptualizing Religion: Immanent Anthropologists, Transcendent Natives, and Unbounded Categories, Studies in the history of religions. Leiden: E.J. Brill.

Skriletz, C. M. 2012. 'Wisteria, Cherry Trees, and Mountains: Presenting a New Model for Understanding Buddhist Communities in the United States.' Master of Arts Dissertation?, Religious Studies, University of Colorado.

Storhoff, G. and J. Whalen-Bridge, eds. 2010. American Buddhism as a Way of Life, SUNY series in Buddhism and American culture. Albany: State University of New York Press.

Taylor, C. 2007. A Secular Age. Cambridge, MA: Belknap Press of Harvard University Press.

Tweed, T. A. 2002. 'Who Is a Buddhist?: Night-Stand Buddhists and Other Creatures.' In Westward Dharma: Buddhism Beyond Asia, edited by C. S. Prebish and Martin Baumann, 17-33. Berkeley: University of California Press.

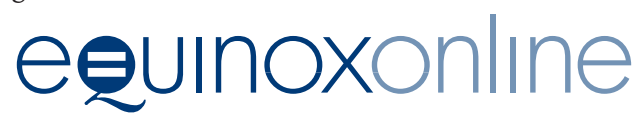


2011. 'Theory and Method in the Study of Buddhism: Toward 'Translocative' Analysis.' Journal of Global Buddhism 12: 17-32.

Varela, F. J. and N. Depraz. 2003. 'Imagining: Embodiment, Phenomenology and Transformation.' In Buddhism \& Science: Breaking New Ground, edited by B. A. Wallace, 193-230. New York: Columbia University Press.

Wilson, J. 2012. Dixie Dharma: Inside a Buddhist Temple in the American South. Chapel Hill: University of North Carolina Press. http://dx.doi.org/10.5149/9780807869970_wilson 